\title{
Glucocorticoid with cyclophosphamide for paraquat-induced lung fibrosis (Review)
}

\author{
Li LR, Sydenham E, Chaudhary B, You C
}

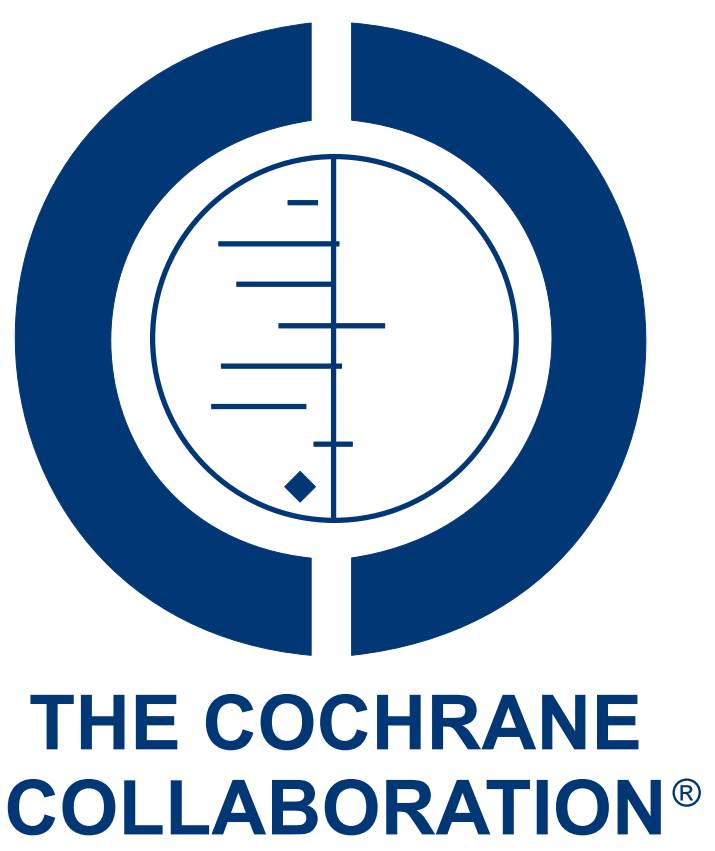

This is a reprint of a Cochrane review, prepared and maintained by The Cochrane Collaboration and published in The Cochrane Library 2010, Issue 6

http://www.thecochranelibrary.com

\section{WILEY}

Glucocorticoid with cyclophosphamide for paraquat-induced lung fibrosis (Review)

Copyright @ 2010 The Cochrane Collaboration. Published by John Wiley \& Sons, Ltd. 


\section{TABLE OF CONTENTS}

HEADER . . . . . . . . . . . . . . . . . . . . . . . . . . . . . . . . . . . . . . . . 1

ABSTRACT . . . . . . . . . . . . . . . . . . . . . . . . . . . . . . . . . . . . . . . . . . . . . 1

PLAIN LANGUAGE SUMMARY . . . . . . . . . . . . . . . . . . . . . . . . . . . . . . . . . . . . .

BACKGROUND . . . . . . . . . . . . . . . . . . . . . . . . . . . . . . . . . . . . . 42

OBJECTIVES . . . . . . . . . . . . . . . . . . . . . . . . . . . . . . . . . . . . . . . . .

METHODS . . . . . . . . . . . . . . . . . . . . . . . . . . . . . . . . . . . . . . . . . . .

RESULTS . . . . . . . . . . . . . . . . . . . . . . . . . . . . . . . . 5

Figure 1. . . . . . . . . . . . . . . . . . . . . . . . . . . . . . . . . . . . . .

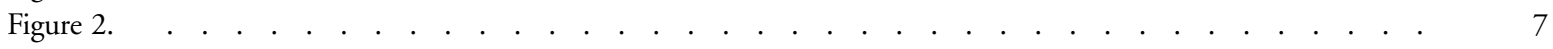

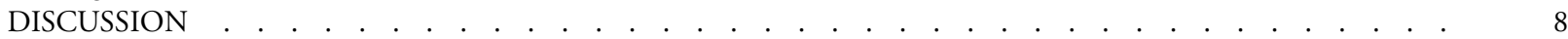

AUTHORS' CONCLUSIONS . . . . . . . . . . . . . . . . . . . . . . . . . . . . . . . . . . . .

ACKNOWLEDGEMENTS . . . . . . . . . . . . . . . . . . . . . . . . . . . . . . . . . . . . . . . . . 8

REFERENCES . . . . . . . . . . . . . . . . . . . . . . . . . . . . . . . . . . . . . . 8

CHARACTERISTICS OF STUDIES . . . . . . . . . . . . . . . . . . . . . . . . . . . . . . . 9

DATA AND ANALYSES . . . . . . . . . . . . . . . . . . . . . . . . . . . . . . . . . . . . . . . . . . . . . . . . . 15

Analysis 1.1. Comparison 1 All-cause mortality at final follow-up, Outcome 1 All-cause mortality at final follow-up. 15

APPENDICES . . . . . . . . . . . . . . . . . . . . . . . . . . . . . . . . . . . . . . . . . . . . . . . . . . 15

HISTORY . . . . . . . . . . . . . . . . . . . . . . . . . . . . . . . . . . . . . . . 18

CONTRIBUTIONS OF AUTHORS . . . . . . . . . . . . . . . . . . . . . . . . . . . . . . . . . . . . . . .

DECLARATIONS OF INTEREST . . . . . . . . . . . . . . . . . . . . . . . . . . . . . . . . . . 18

DIFFERENCES BETWEEN PROTOCOL AND REVIEW . . . . . . . . . . . . . . . . . . . . . . . . . . . . . 18

INDEX TERMS . . . . . . . . . . . . . . . . . . . . . . . . . . . . . . . . . . . . . . . . . . . . 19 
[Intervention Review]

\title{
Glucocorticoid with cyclophosphamide for paraquat-induced lung fibrosis
}

\author{
Luying Ryan $\mathrm{Li}^{1}$, Emma Sydenham ${ }^{2}$, Bhuwan Chaudhary ${ }^{3}$, Chao You ${ }^{1}$ \\ ${ }^{1}$ Department of Neurosurgery, West China Hospital, Chengdu, China. ${ }^{2}$ Cochrane Injuries Group, London School of Hygiene \& \\ Tropical Medicine, London, UK. ${ }^{3}$ West China Medical School, Chengdu, China \\ Contact address: Luying Ryan Li, Department of Neurosurgery, West China Hospital, No.37 Guoxue Xiang, Chengdu, Sichuan, \\ 610041, China. lirang58@hotmail.com.
}

Editorial group: Cochrane Injuries Group.

Publication status and date: New, published in Issue 6, 2010.

Review content assessed as up-to-date: 14 September 2009.

Citation: Li LR, Sydenham E, Chaudhary B, You C. Glucocorticoid with cyclophosphamide for paraquat-induced lung fibrosis. Cochrane Database of Systematic Reviews 2010, Issue 6. Art. No.: CD008084. DOI: 10.1002/14651858.CD008084.pub2.

Copyright (C) 2010 The Cochrane Collaboration. Published by John Wiley \& Sons, Ltd.

\section{A B S T R A C T}

\section{Background}

Paraquat is an effective and widely used herbicide but is also a lethal poison. In many developing countries paraquat is widely available and inexpensive, making poisoning prevention difficult. However most of the people who become poisoned from paraquat have taken it as a means of suicide.

Standard treatment for paraquat poisoning both prevents further absorption and reduces the load of paraquat in the blood through haemoperfusion or haemodialysis. The effectiveness of standard treatments is extremely limited.

The immune system plays an important role in exacerbating paraquat-induced lung fibrosis. Immunosuppressive treatment using glucocorticoid and cyclophosphamide in combination is being developed and studied.

\section{Objectives}

To assess the effects of glucocorticoid with cyclophosphamide on mortality in patients with paraquat-induced lung fibrosis.

\section{Search methods}

To identify randomised controlled trials on this topic, we searched the Cochrane Injuries Group's Specialised Register (searched 15 Sept 2009), CENTRAL (The Cochrane Library 2009, Issue 3), MEDLINE (Ovid SP) (1950 September Week 1 2009), EMBASE (Ovid SP) (1980 to 2009 Week 37), ISI Web of Science: Science Citation Index Expanded (SCI-EXPANDED) (1970 to Sept 2009), ISI Web of Science: Conference Proceedings Citation Index - Science (CPCI-S) (1990 to Sept 2009), Chinese bio-medical literature \& retrieval system (CBM) (1978 to Sept 2009), Chinese medical current contents (CMCC) (1995 to Sept 2009), and Chinese medical academic conference (CMAC) (1994-Sept 2009). The searches were completed in September 2009.

\section{Selection criteria}

Randomised controlled trials (RCTs) were included in this review. All patients were to receive standard care, plus the intervention or control. The intervention was glucocorticoid with cyclophosphamide in combination versus a control of a placebo, standard care alone, or any other therapy in addition to standard care.

Glucocorticoid with cyclophosphamide for paraquat-induced lung fibrosis (Review)

Copyright $\odot 2010$ The Cochrane Collaboration. Published by John Wiley \& Sons, Ltd. 


\section{Data collection and analysis}

The mortality risk ratio (RR) and 95\% confidence interval (CI) was calculated for each study on an intention-to-treat basis. Data for all-cause mortality at final follow-up were summarised in a meta-analysis using a fixed-effects model.

\section{Main results}

This systematic review includes three trials with a combined total of 164 participants who had moderate to severe paraquat poisoning. Patients who received glucocorticoid with cyclophosphamide in addition to standard care had a lower risk of death at final follow-up than those receiving standard care only (RR 0.72 (95\% CI 0.59 to 0.89$)$ ).

\section{Authors' conclusions}

Based on the findings of three small RCTs of moderate to severely poisoned patients, glucocorticoid with cyclophosphamide in addition to standard care may be a beneficial treatment for patients with paraquat-induced lung fibrosis. To enable further study of the effects of glucocorticoid with cyclophosphamide for patients with moderate to severe paraquat poisoning, hospitals may provide this treatment as part of an RCT with allocation concealment.

\section{PLAIN LANGUAGE SUMMARY}

\section{Using steroids and cyclophosphamide together may reduce deaths from paraquat poisoning}

Paraquat is an effective and widely used herbicide but is also a lethal poison. In many developing countries paraquat is widely available and inexpensive, making poisoning prevention difficult. However most of the people who become poisoned from paraquat have taken it as a means of suicide.

Standard care for removing paraquat from the body involves vomiting, consuming activated charcoal or Fuller's Earth (which absorbs paraquat), and blood filtering. This review aims to assess the effects of giving patients steroids and cyclophosphamide in addition to standard care to prevent death after paraquat poisoning.

We found three small randomised controlled trials in which patients with moderate or severe poisoning were given either standard care only or standard care and steroids and cyclophosphamide. When the results of the three studies were combined, we found that patients who were given standard care and steroids and cyclophosphamide had a reduced risk of death of about 28\% (statistically estimated range from $41 \%$ to $11 \%$ ) compared with patients given standard care alone. However, the studies were small and one was of low methodological quality so this finding should be interpreted with caution. To better understand the effects of this intervention for poisoned patients, we recommend treatment be given in the context of a randomised controlled trial so that future results can be analysed with similar studies.

\section{B A C K G R O U N D}

Paraquat is one of the most widely used herbicides worldwide. It is commercially produced and has been sold in around 130 countries since 1961, despite its fatal toxicity to humans (Tomlin 1994). Because it is inexpensive and widely available, it is difficult to prevent paraquat poisoning. Paraquat poisoning by accidental or voluntary ingestion accounts for numerous deaths each year, predominantly in developing countries where its use is less stringently controlled than in Europe or the United States.

An epidemiologic study of poisoning in rural Sri Lanka found an incidence of poisoning of 75 per 100,000 population, with a death rate up to 22 per 100,000 population. The incidence and death rates from poisoning were highest in the 15-34 age group, and there were significant differences in the incidence of poisoning among different ethnic groups. In this study, paraquat was the most common poisoning agent (Hettiarachchi 1989).

In China, paraquat poisoned patients are usually women and children in impoverished rural areas, who are not well-educated and are often unfairly treated. In many cases, the decision to drink paraquat is impulsive and follows an intense interpersonal conflict (Wang 2008). 


\section{Description of the condition}

The prognosis in paraquat poisoning is associated with the amount of toxin ingested:

- In low dose poisoning (<20 mg of paraquat ion per $\mathrm{kg}$ of body weight) patients are often asymptomatic, or may develop vomiting or diarrhoea, but have a good chance of recovery.

- In moderate dose poisoning patients (20 to $40 \mathrm{mg}$ of paraquat ion per kg of body weight), initial renal and hepatic dysfunction is common. Mucosal damage may become apparent with sloughing of the mucous membranes in the mouth. Difficulty in breathing may develop after a few days in the more severe cases. After about 10 days, although renal function often returns to normal, radiological signs of lung damage usually develop. Lung damage is usually followed by irreversible massive pulmonary fibrosis manifested by the progressive loss of the lungs' ability to breathe, and deterioration continues until the patient eventually dies, between 2 to 4 weeks after ingestion.

- In high dose poisoning patients (>40 mg paraquat ion per $\mathrm{kg}$ of body weight), toxicity is much more severe and death occurs early (within 24-48 hrs) from multiple organ failure. Vomiting and diarrhoea are severe, with considerable fluid loss. Renal failure, cardiac arrhythmias, coma, convulsions, and oesophageal perforation leads to death (WHO 2009).

\section{Description of the intervention}

The care of a paraquat poisoned person involves reducing the quantity of paraquat ingested and removing paraquat from the bloodstream. Vomiting should be induced as soon as possible to prevent further absorption of the toxin (Dinham 1996). Upon arrival at the emergency room, further interventions may include gastric aspiration, gastric lavage, repeated administration of the absorbents activated charcoal or Fuller's Earth, and purgatives such as mannitol or sorbitol (WHO 2009). Haemodialysis, haemofiltration, and haemoperfusion could be instituted in the aim to reduce the load of poison in the blood, but these interventions have no proven effects for improving survival (Suzuki 1993; Koo 2002), mainly because paraquat accumulates in the lungs.

Paraquat molecules selectively accumulate in the lungs, leading to irreversible pulmonary fibrosis which is also known as 'paraquat lung' (Smith 1975; Fukuda 1985). This accumulation process begins immediately after ingestion and lasts from 2 to 4 weeks. A large proportion of patients appear asymptomatic until signs of breathing difficulty emerge; it is difficult to predict the outcome of a patient who appears normal but is actually suffering lung fibrosis (Eddleston 2003).

While numerous methods are available to reduce paraquat concentration in the blood stream, the progression of lung injury through the deposited paraquat is a major concern. The combination of glucocorticoid combined with cyclophosphamide as a means of suppressing the immunoreactions which cause lung damage has been tested since the 1970s (Eddleston 2003), but the effectiveness of this treatment is unknown. The timing of providing treatment, the duration of treatment, and the dosage of drugs can vary depending on the needs of the patient.

\section{How the intervention might work}

After being actively accumulated by lung cells, paraquat catalyses the formation of certain chemicals, namely superoxide, singlet oxygen, hydroxyl, and peroxide radicals. These chemicals are also used by the immune system as 'weapons' to destroy items recognised as foreign to the human body (Smith 1988). It is believed that immunosuppressive methods will prevent the immune system from producing such chemicals thereby reducing damage. At the same time, the immunosuppressive agents are intended to halt the progress of fibrosis, which is a part of immune reaction (Jaeschke 1997).

\section{Why it is important to do this review}

Though it has been inferred from experiment (Lee 1984) and clinical experience (Agarwal 2006) that immunosuppressive therapy might reduce deaths in paraquat poisoned patients, there has been no conclusion on the effectiveness of this treatment. Considering the hazards associated with immunosuppressive drugs (Winsett 2004), for example by making patients more prone to infection in the long term, it is timely to have a systematic review on this topic to support decision-making or suggest further research.

\section{O B J E C T I VES}

To assess the effects of glucocorticoid with cyclophosphamide on mortality in patients with paraquat-induced lung fibrosis.

\section{METHODS}

\section{Criteria for considering studies for this review}

\section{Types of studies}

Randomised controlled trials (RCTs) were included.

\section{Types of participants}

Any person with paraquat poisoning. 


\section{Types of interventions}

All patients were to receive standard care plus either the intervention or control.

- Intervention: Glucocorticoid with cyclophosphamide in combination.

- Control: Placebo, standard care alone, or any other therapy in addition to standard care.

Studies that focused on any single immunosuppressant or other combinations of therapies were excluded.

\section{Types of outcome measures}

- Mortality at 30 days following the ingestion of paraquat.

- All-cause mortality at the end of the follow-up period.

\section{Search methods for identification of studies}

The search was not restricted by date, language or publication status.

\section{Electronic searches}

Electronic searches were carried out in both English and Chinese databases.

We searched the following English language databases;

- Cochrane Injuries Group's Specialised Register (searched 15 Sept 2009),

- CENTRAL (The Cochrane Library 2009, Issue 3),

- MEDLINE (Ovid SP) 1950 September Week 12009 ,

- EMBASE (Ovid SP) 1980 to 2009 Week 37,

- ISI Web of Science: Science Citation Index Expanded (SCIEXPANDED) 1970 to Sept 2009,

- ISI Web of Science: Conference Proceedings Citation Index- Science (CPCI-S) 1990 to Sept 2009.

The search strategies are reported in full in Appendix 3.

We searched the following Chinese language databases using the search strategy reported in Appendix 2, (which is a modified and translated version of the strategy formulated by the Cochrane Injuries Group's Trials Search Coordinator in Appendix 1);

- Chinese bio-medical literature \& retrieval system (CBM) (1978-September 2009),

- Chinese medical current contents (CMCC) (1995September 2009),

- Chinese medical academic conference (CMAC) (1994September 2009).

Due to the paucity of trials in this area, we did not restrict our search by using a filter to identify only RCTs. We sought all types of trials in the hope we might identify RCTs that may have otherwise been overlooked.
We searched the following two trial registers using the term 'paraquat':

- Clinicaltrials.gov,

- Controlled-trials.com.

\section{Searching other resources}

We searched the Internet through search engines Google.com and Baidu.com, using the term 'clinical trial \& paraquat'. We also checked the reference lists of reports and literature reviews on paraquat poisoning for potentially relevant published or unpublished trials. We contacted the authors of the included trials for further information.

\section{Data collection and analysis}

\section{Selection of studies}

The search results from English language databases were screened independently by LL and BC. The results from the Chinese databases were screened independently by LL and YC. The full text versions of potentially relevant trials were obtained and assessed. Duplicate reports were identified and noted. LL and BC disagreed about the inclusion of the Afzali 2008 study due to the use of alternation as the method of randomisation. YC moderated the discussion on inclusion of this trial, and it was agreed that the trial would be included but noted as being of high risk of bias.

\section{Data extraction and management}

Data from the three included trials were extracted independently by LL, BC and ES. Data were extracted on the study design, number of participants in the intervention and control groups, the number of deaths in each group on an intention-to-treat basis, and loss to follow-up in each trial. Information on the methodology of each trial was recorded for assessment of the risk of bias, as described below. Data were analysed using Review Manager software.

\section{Assessment of risk of bias in included studies}

Three authors (LL, BC and ES) independently evaluated the risk of bias for each included trial in the following domains: sequence generation, allocation concealment, blinding, incomplete reporting, selective outcome reporting and any other sources of bias. To facilitate a valid judgement, we wrote to the contact person for each trial to request further information. Our judgement was made according to the criteria defined by (Higgins 2008), where 'Yes' means low risk of bias, 'Unclear' means not enough information was provided to make a judgement, and 'No' means there is potential for high risk of bias. The judgements can be found in 
the risk of bias tables below, and a summary of the judgements are in Figure 1 and 2.

\section{Measures of treatment effect}

The risk ratio (RR) and 95\% confidence interval (CI) was calculated for each trial on an intention-to-treat basis. Data for all-cause mortality at final follow-up were summarised in a meta-analysis using a fixed-effects model.

\section{Dealing with missing data}

The amount of loss to follow-up in each trial was assessed.

\section{Assessment of heterogeneity}

Clinical heterogeneity was assessed by considering the design of each trial. Where suspicion of clinical heterogeneity arose, the differences in study design among trials was considered.

Where possible and appropriate, the statistical heterogeneity was examined using the $\mathrm{Chi}^{2}$ test. A p-value below 0.10 indicated heterogeneity but was interpreted with caution. The $\mathrm{I}^{2}$ statistic was calculated to assess the attribution of heterogeneity to the diversity of results from different trials.

\section{Assessment of reporting biases}

Due to the small number of trials included in the review, we did not investigate reporting bias through a funnel plot.

\section{R E S U L T S}

\section{Description of studies}

See: Characteristics of included studies; Characteristics of excluded studies; Characteristics of ongoing studies.

\section{Results of the search}

The electronic searches for studies retrieved 576 records. Of these records 506 were excluded due to irrelevance to paraquat or duplication. From the remaining 70 studies, we identified 3 randomised controlled trials.

LL identified 768 reports through a Chinese language search on Chinese language databases; none of them met the inclusion criteria.
LL identified one ongoing RCT which is described in the 'Characteristics of ongoing studies' section below.

LL identified one report while searching Google.com using the term 'clinical trial \& paraquat' which was later excluded (Tsai 2009). No additional eligible randomised trials were identified through screening reference lists or literature reviews.

\section{Included studies}

Three trials with a combined total of 164 participants are included in this review (Afzali 2008, Lin 1999, Lin 2006). All three compared the use of standard care alone versus standard care and glucocorticoid with cyclophosphamide for patients with paraquat poisoning. Mortality at final follow-up was the primary outcome in all three trials.

All three trials included moderate to severely paraquat poisoned patients who had a urine sodium dithionite test reaction of dark blue or navy blue. The Lin 2006 trial had an additional inclusion criteria of a predicted mortality of $>50 \%$ and $\leq 90 \%$ according to the Hart 1984 formula. (Readers of the review should therefore bear in mind that the trials included in the review had slightly different inclusion criteria and should interpret the findings of the review accordingly.) Patients with mild paraquat poisoning were not included in any trial.

\section{Excluded studies}

Two trials were excluded: in one trial the intervention was methylprednisolone only (Tsai 2009), and the other was a historical controlled trial (Perriens 1992).

\section{Risk of bias in included studies}

The trial by Lin 2006 had a relatively low risk of bias. The trial by Lin 1999 randomised all urine positive patients but presented the outcomes for those who died within one week of poisoning separately from those who survived longer. Presenting the data separately is reasonable to a certain extent given the specific clinical features of paraquat poisoning, but also suggests reporting bias. The exact methods used for patient selection, randomisation, and sequence concealment were not reported in the Afzali 2008 study but we were able to gain the necessary details through contact with the author and determined that the trial is at high risk of bias. Our judgements of the risk of bias are recorded in the risk of bias tables, and are displayed in Figure 1 and Figure 2. 
Figure I. Methodological quality graph: review authors' judgements about each methodological quality item presented as percentages across all included studies. Three studies are included in this review.

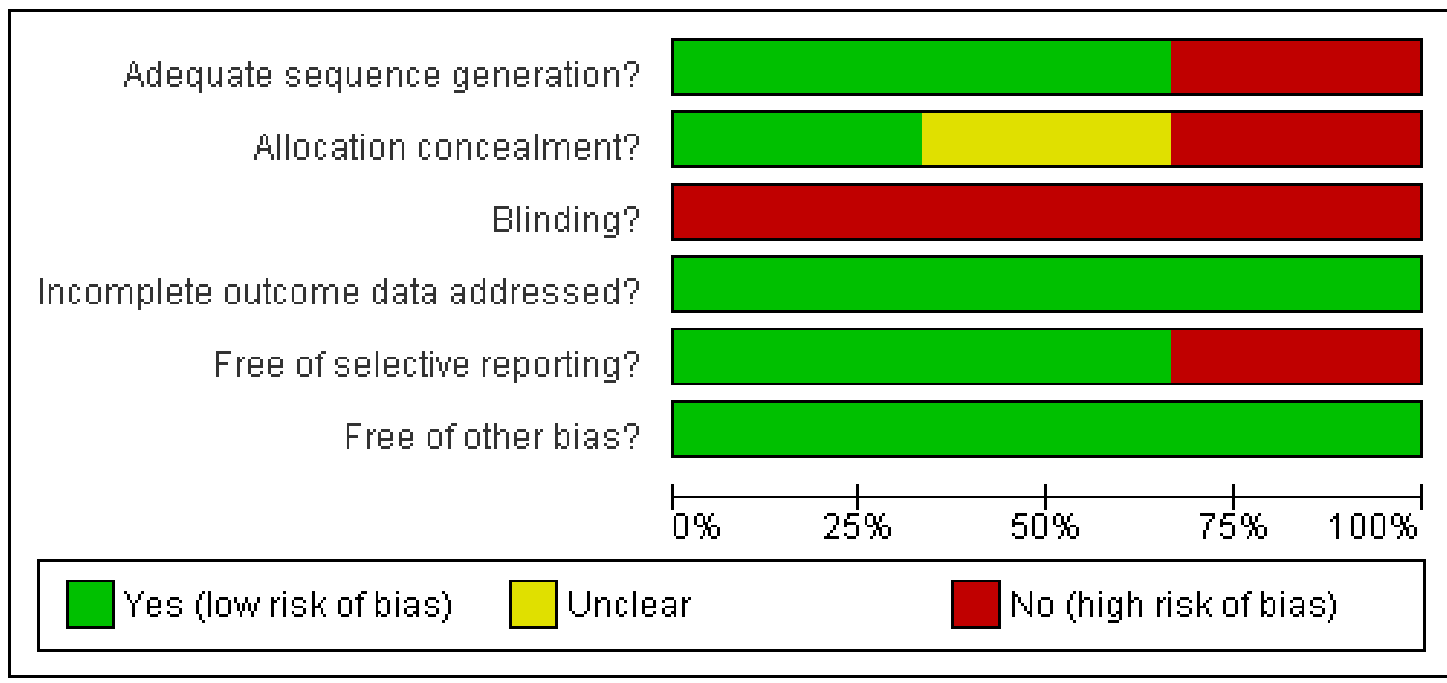


Figure 2. Methodological quality summary: review authors' judgements about each methodological quality item for each included study.

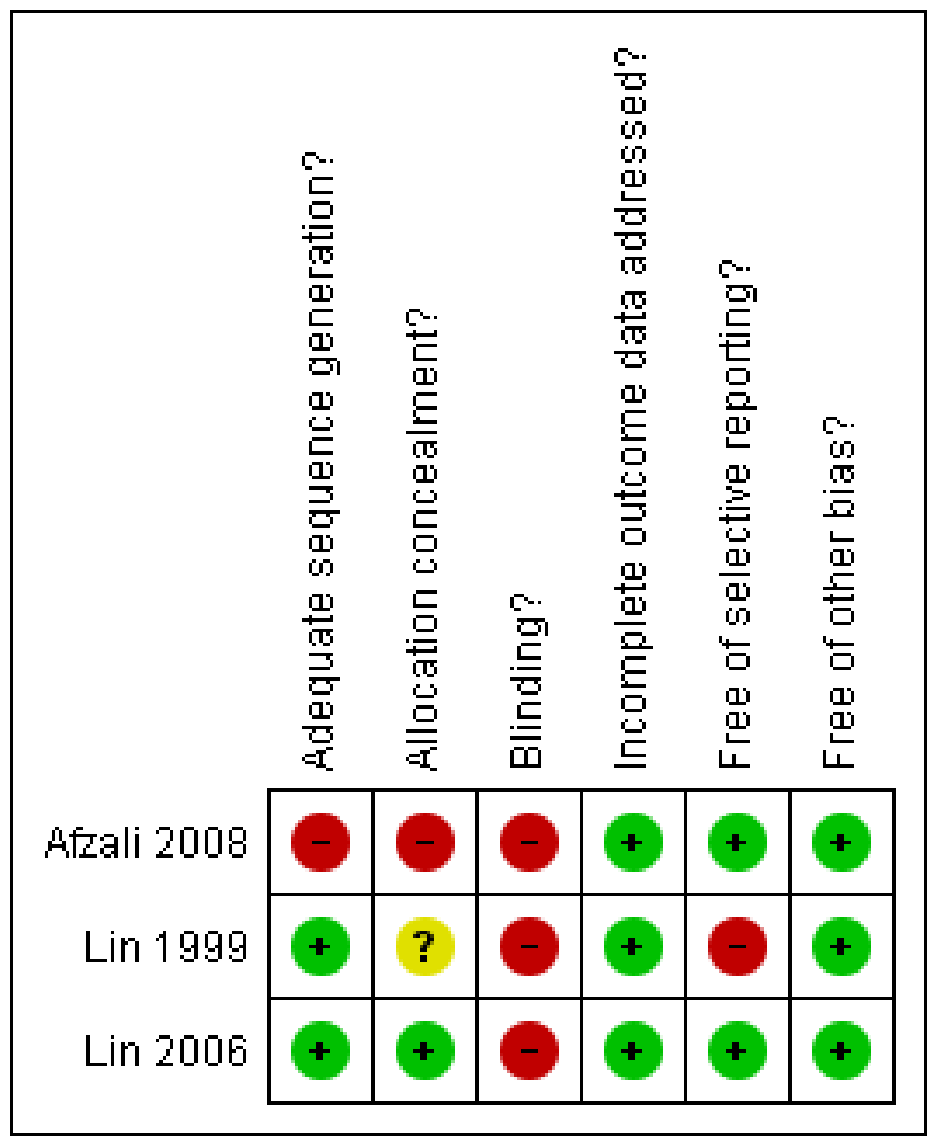

\section{Allocation}

The Lin 2006 study used an appropriate method of sequence generation and allocation concealment. Lin 1999 generated the randomisation sequence using a random number table, but did not conceal the sequence. Afzali 2008 used alternation with no concealment, according to the author.

\section{Blinding}

None of the trials mentioned blinding of the treating physicians or patients. In Lin 1999 and Lin 2006 the statistician who contributed to the trial report was blinded to the allocation.

\section{Incomplete outcome data}

Mortality was the outcome of interest, and was reported in full in all trials.

\section{Selective reporting}

There was no selective reporting of mortality. The Lin 1999 study presented the mortality data by severity of poisoning and randomisation group which appears to have been a post-hoc decision in the style of presenting results. However, we analysed the data according to intention-to-treat which maintained the original randomisation.

\section{Other potential sources of bias}

No other potential source of bias was found.

\section{Effects of interventions}

- All-cause mortality at the end of the follow-up period.

Analysis 1.1

All three trials reported death at the end of the follow-up period. Patients who received glucocorticoid with cyclophosphamide in 
addition to standard care had a lower risk of death than those receiving standard care alone (RR 0.72 (95\% CI 0.59 to 0.89 )). There was some statistical heterogeneity between trials $\left(\mathrm{Chi}^{2}=\right.$ 5.96, $\left.\mathrm{df}=2(\mathrm{P}=0.05) ; \mathrm{I}^{2}=66 \%\right)$.

- Mortality at 30 days following the ingestion of paraquat.

This outcome was not reported in any of the studies.

\section{DISCUSSION}

\section{Summary of main results}

This systematic review includes three trials (one of low methodological quality) with a combined total of 164 participants who had moderate to severe paraquat poisoning. Participants who received glucocorticoid with cyclophosphamide in addition to standard care had a lower rate of death than those receiving standard care alone.

\section{Overall completeness and applicability of evidence}

There are few RCTs involving paraquat poisoned patients. The review includes three small RCTs, one of which is of low quality. A larger RCT is currently recruiting patients in Sri Lanka and data from this study will be included in this review when available. To enable further study of the effects of glucocorticoid and cyclophosphamide for paraquat poisoned patients, hospitals should provide this treatment as part of an RCT with allocation concealment. The findings of this review should be interpreted with caution until more data becomes available.

\section{Potential biases in the review process}

This review was conducted according to predefined inclusion criteria and methodology to select and appraise eligible studies. The search for trials was extensive, and was conducted on English and Chinese language databases. Publication bias is a consideration in any systematic review. Although there are only three small trials included in this review, we believe that due to the extent of the search for trials, these were the only RCTs addressing this research question at the time of the search.

\section{AUTHORS' CONCLUSIONS}

\section{Implications for practice}

Based on the findings of three small RCTs of moderate to severely poisoned patients, glucocorticoid with cyclophosphamide in addition to standard care may be beneficial for patients with paraquatinduced lung fibrosis. The finding of this review should be interpreted with caution until more data become available.

\section{Implications for research}

To enable further study of the effects of glucocorticoid with cyclophosphamide for patients with moderate to severe paraquat poisoning, hospitals may provide this treatment as part of an RCT with allocation concealment.

\section{ACKNOW LEDGEMENTS}

We thank Karen Blackhall for providing the search strategy and the search of English language databases.

\section{R E F E R E N C E S}

\section{References to studies included in this review}

Afzali 2008 \{published data only\}

Afzali S, Gholyaf M. The effectiveness of combined treatment with methylprednisolone and cyclophosphamide in oral paraquat poisoning. Archives of Iranian Medicine 2008;11(4):387-91.

Lin 1999 \{published data only\}

Lin JL, Leu ML, Liu YC, Chen GH. A prospective clinical trial of pulse therapy with glucocorticoid and cyclophosphamide in moderate to severe paraquat-poisoned patients. American Journal of Respiratory and Critical Care Medicine 1999;159:357-60.

Lin 2006 \{published data only\} Lin JL, Lin-Tan DT, Chen KH, Huang WH. Repeated pulse of methylprednisolone and cyclophosphamide with continuous dexamethasone therapy for patients with severe paraquat poisoning. Critical Care Medicine 2006;34(2): 368-73.

References to studies excluded from this review

Perriens 1992 \{published data only\}

Perriens JH, Benimadho S, Kiauw IL, Wisse J, Chee $\mathrm{H}$. High-dose cyclophosphamide and dexamethasone in paraquat poisoning: a prospective study. Human and Experimental Toxicology 1992;11(2):129-34.

Tsai 2009 \{published data only\}

Tsai J, Lee R, Wang C, Fang T, Hsu B. A clinical study of prognosis and glucocorticoid pulse treatment in patients 
with acute paraquat intoxication. Tzu Chi Medical Journal 2009;21(2):156-60.

\section{References to ongoing studies}

\section{Ariyananda 2006 \{published data only\}}

A randomised controlled trial of high-dose immunosuppression in paraquat poisoning. (ISRCTN85372848). Ongoing study 30 August 2006.

\section{Additional references}

\section{Agarwal 2006}

Agarwal R, Srinivas R, Aggarwal AN, Gupta D. Experience with paraquat poisoning in a respiratory intensive care unit in North India. Singapore Medical Journal 2006;47(12): 1037.

\section{Dinham 1996}

Dinham B. Active ingredient fact sheet: Paraquat. PAN UK: Pesticide News No. 32 2003:20-1.

\section{Eddleston 2003}

Eddleston M, Wilks MF, Buckley NA. Prospects for treatment of paraquat-induced lung fibrosis with immunosuppressive drugs and the need for better prediction of outcome: a systematic review. QJM: An International Journal of Medicine 2003;96:809-24.

\section{Fukuda 1985}

Fukuda Y, Ferrans VJ, Schoenberger CI, Rennard SI, Crystal RG. Patterns of pulmonary structural remodeling after experimental paraquat toxicity. The morphogenesis of intraalveolar fibrosis. The American Journal of Medicine 1985;118(3):452-75.

\section{Hart 1984}

Hart TB, Nevitt A, Whitehead A. A new statistical approach to the prognostic significance of plasma concentrations. Lancet 1984;ii: $1222-3$.

\section{Hettiarachchi 1989}

Hettiarachchi J, Kodithuwakku GCS. Pattern of poisoning in rural Sri Lanka. International Journal of Epidemiology 1989;18:418-22.

Higgins 2008

Higgins JPT, Green S. Cochrane Handbook for Systematic Reviews of Interventions. Version 5.0.1 [updated September 2008]. The Cochrane Collaboration, 2008. Available from www.cochrane-handbook.org.

\section{Jaeschke 1997}

Jaeschke H, Smith CW. Mechanisms of neutrophil-induced parenchyma injury. Journal of Leukocyte Biology 1997;61: $647-53$.
Koo 2002

Koo J, Kim J, Yoon J, Kim G, Jeon R, Kim H, Chae D, Noh J. Failure of continuous venovenous hemofiltration to prevent death in paraquat poisoning. American Journal of Kidney Diseases 2002;39:55-9.

Lee 1984

Lee SS, Kawanami O, Aihara K, Chung CH, Hirohata Y. Paraquat intoxication on rat lung. Korean Journal of Pathology 1984;18(4):333.

\section{Review Manager}

The Nordic Cochrane Centre. Review Manager. 5.0. Copenhagen: The Cochrane Collaboration, 2008.

\section{Smith 1975}

Smith P, Heath D. The pathology of the lung in paraquat poisoning. Journal of Clinical Pathology 1975;9:81-93.

\section{Smith 1988}

Smith LL. The toxicity of paraquat. Adverse Drug Reactions and Acute Poisoning Reviews 1988;1:1-17.

\section{Suzuki 1993}

Suzuki K, Takasu N, Okabe T, Ishimatsu S, Ueda A, Tanaka S, Fukuda A, Arita S, Kohama A. Effect of aggressive haemoperfusion on the clinical course of patients with paraquat poisoning. Human and Experimental Toxicology 1993;12:323-7.

\section{Tomlin 1994}

Tomlin C. The Pesticide Manual. 10th Edition. Farnham UK: British Crop Protection Council and the Royal Society of Chemistry, 1994.

\section{Wang 2008}

Wang SY, Li YH, Chi GB, Xiao SY, Ozanne-Smith J, Stevenson M, Phillips MR. Injury-related fatalities in China: an under-recognised public-health problem. www.thelancet.com Published online October 20, 2008. [DOI: 10.1016/S0140-6736(08)61367-7]

\section{WHO 2009}

Word Health Organization. Poison information monograph 399. Paraquat. International programme for chemical safety. March 26, 2009.

\section{Winsett 2004}

Winsett RP, Arheart K, Stratta RJ, Alloway R, Wicks $\mathrm{MN}$, Gaber AO, Hathaway DK. Evaluation of an immunosuppressant side effect instrument. Progress in Transplantation 2004;14(3):210-6, 240.

* Indicates the major publication for the study 


\section{CHARACTERISTICS OF STUDIES}

\section{Characteristics of included studies [ordered by study ID]}

\section{Afzali 2008}

\begin{tabular}{|c|c|c|}
\hline Methods & \multicolumn{2}{|c|}{ Randomised controlled trial. } \\
\hline Participants & \multicolumn{2}{|c|}{$\begin{array}{l}\text { Patients with moderate to severe paraquat poisoning. Poisoning was determined by a } \\
\text { navy blue or dark blue result of a urine sodium dithionite test }\end{array}$} \\
\hline Interventions & \multicolumn{2}{|c|}{$\begin{array}{l}\text { All patients received: '...fixation of a nasogastric tube, gastric lavage with normal saline, } \\
\text { charcoal-sorbitol gavage every two to four hours for three days, forced alkalinised diuresis } \\
\text { in the first day of admission to the hospital, and haemodialysis of four hours duration } \\
\text { for both groups.' p. } 388 \\
\text { The intervention group also received: '...15 } \mathrm{mg} / \mathrm{kg} \text { of cyclophosphamide in dextrose } \\
\text { saline }(200 \mathrm{~mL} \text { ) was infused in two hours for two days. Methylprednisolone, one gram } \\
\text { in } 200 \mathrm{~mL} \text { dextrose saline was also infused for four hours and was repeated for three } \\
\text { consecutive days. Meanwhile, } 15 \mathrm{mg} / \mathrm{kg} \text { of mesna was prescribed (for four days) in order } \\
\text { to avoid the side effects of cyclophosphamide.' p. } 388\end{array}$} \\
\hline Outcomes & \multicolumn{2}{|l|}{ Mortality. } \\
\hline Notes & \multicolumn{2}{|c|}{$\begin{array}{l}\text { Recruitment was from September } 2003 \text { to October } 2005 \text {. } \\
\text { Intervention group: } 9 \text { participants. } 8 \text { were male, } 1 \text { was female. Poisoning severity: } 3 \text { navy } \\
\text { blue, } 6 \text { dark blue } \\
\text { Control group: } 11 \text { participants. } 8 \text { were male, } 3 \text { were female. Poisoning severity: } 4 \text { navy } \\
\text { blue, } 7 \text { dark blue }\end{array}$} \\
\hline \multicolumn{3}{|l|}{ Risk of bias } \\
\hline Item & Authors' judgement & Description \\
\hline Adequate sequence generation? & No & $\begin{array}{l}\text { We contacted the author of the study, who told us alter- } \\
\text { nation was used }\end{array}$ \\
\hline Allocation concealment? & No & $\begin{array}{l}\text { The study author told us there was no allocation con- } \\
\text { cealment }\end{array}$ \\
\hline $\begin{array}{l}\text { Blinding? } \\
\text { All outcomes }\end{array}$ & No & $\begin{array}{l}\text { Blinding was not reported and, according to the author, } \\
\text { was not done }\end{array}$ \\
\hline $\begin{array}{l}\text { Incomplete outcome data addressed? } \\
\text { All outcomes }\end{array}$ & Yes & $\begin{array}{l}\text { The main outcome was death at final follow-up, and this } \\
\text { was reported in full }\end{array}$ \\
\hline Free of selective reporting? & Yes & $\begin{array}{l}\text { The study reported the main outcome, death at final } \\
\text { follow-up, in full }\end{array}$ \\
\hline Free of other bias? & Yes & We did not identify any other areas of bias. \\
\hline
\end{tabular}

Glucocorticoid with cyclophosphamide for paraquat-induced lung fibrosis (Review) 


\begin{tabular}{|c|c|c|}
\hline Methods & \multicolumn{2}{|c|}{ Randomised controlled trial. } \\
\hline Participants & \multicolumn{2}{|c|}{$\begin{array}{l}\text { People who had ingested paraquat within the previous } 24 \text { hours, and had a urine sample } \\
\text { which resulted in a navy blue or dark blue reaction to a sodium dithionite test }\end{array}$} \\
\hline Interventions & \multicolumn{2}{|c|}{$\begin{array}{l}\text { All patients received: 'To prevent absorption of paraquat from the gastrointestinal tract, } \\
\text { active charcoal added in magnesium citrate was given through a nasogastric tube after } \\
\text { gastric lavage with normal saline. All patients received two courses of } 8 \text {-h active char- } \\
\text { coal haemoperfusion therapy in the emergency room (ER), and dexamethasone } 10 \mathrm{mg} \\
\text { intravenous injection every } 8 \mathrm{~h} \text { was given for } 14 \mathrm{~d} \text { after admission.' p. } 357 \\
\text { The intervention group also received: 'In addition, the study group patients received } \\
\text { pulse therapy after haemoperfusion at ER. Pulse therapy included } 15 \mathrm{~g} / \mathrm{kg} \text { of CP in } 5 \% \\
\text { glucose saline } 200 \mathrm{ml} \text { and } 1 \mathrm{~g} \text { MP in the other } 200 \mathrm{ml} 5 \% \text { glucose saline intravenously } \\
\text { infused for } 2 \mathrm{~h} / \mathrm{d} \text {. CP was infused for } 2 \mathrm{~d} \text { and MP for } 3 \mathrm{~d} \text {.' p. } 357 \\
(\mathrm{CP}=\text { cyclophosphamide; } \mathrm{MP}=\text { methylprednisolone) }\end{array}$} \\
\hline Outcomes & \multicolumn{2}{|l|}{ Mortality. } \\
\hline Notes & \multicolumn{2}{|c|}{$\begin{array}{l}\text { Recruitment was from January } 1992 \text { to December } 1997 . \\
\text { Intervention Group: } 56 \text { participants. } 33 \text { were male, } 23 \text { were female } \\
\text { Control Group: } 65 \text { participants. } 45 \text { were male, } 20 \text { were female }\end{array}$} \\
\hline \multicolumn{3}{|l|}{ Risk of bias } \\
\hline Item & Authors' judgement & Description \\
\hline Adequate sequence generation? & Yes & '...according to random digit methods.' p.357 \\
\hline Allocation concealment? & Unclear & There was no mention of allocation concealment. \\
\hline $\begin{array}{l}\text { Blinding? } \\
\text { All outcomes }\end{array}$ & No & $\begin{array}{l}\text { Blinding of the treating physician and patients was not } \\
\text { reported } \\
\text { 'At the end of this study, to avoid bias, the data were } \\
\text { collected and analysed by other doctors who were not } \\
\text { aware of the study.' p. } 357\end{array}$ \\
\hline $\begin{array}{l}\text { Incomplete outcome data addressed? } \\
\text { All outcomes }\end{array}$ & Yes & $\begin{array}{l}\text { The main outcome was death at final follow-up, and this } \\
\text { was reported in full }\end{array}$ \\
\hline Free of selective reporting? & No & $\begin{array}{l}\text { Information on the primary outcome, mortality is pre- } \\
\text { sented in full. However, the study report authors present } \\
\text { the data according to severity of poisoning, although par- } \\
\text { ticipants were randomised into the study regardless of the } \\
\text { severity of poisoning. We, the authors of this Cochrane } \\
\text { review, have combined the results from the two tables on } \\
\text { page } 358 \text { into the results of this review on an intention- } \\
\text { to-treat basis to maintain the study investigators origi- } \\
\text { nal randomisation }\end{array}$ \\
\hline
\end{tabular}


Lin 1999 (Continued)

Free of other bias?

Yes
We did not identify any other areas of bias. The presentation of results in the study report implies that the intervention is effective in moderately poisoned patients; but we have used an intention-to-treat analysis to summarise the findings in this review which corrects this potential bias

Lin 2006

\begin{tabular}{ll}
\hline Methods & Randomized controlled trial. \\
\hline Participants & $\begin{array}{l}\text { Patients who: } 1 \text { ) arrived at the emergency room within } 24 \text { hours of ingesting paraquat, } \\
\text { 2) were age } 15 \text { years or older, } 3 \text { ) had predicted mortality of }>50 \% \text { and } \leq 90 \% \text { according } \\
\text { to the Hart } 1984 \text { formula, and } 4 \text { ) had urine sodium dithionite tests showing the colour } \\
\text { dark blue or navy blue. }\end{array}$ \\
$\begin{array}{l}\text { The exclusion criteria were: 'Patients were excluded from the study if they had dermal } \\
\text { exposure to paraquat; received intravascular injection of paraquat; did not have paraquat } \\
\text { levels in biological fluids; arrived at the emergency room }>24 \text { hours after ingestion of } \\
\text { paraquat; ingested paraquat due to major systemic diseases including cancer and heart, } \\
\text { lung, renal, and liver diseases; or did not give informed consent.' p.369 }\end{array}$
\end{tabular}

Interventions

All patients received: 'To prevent absorption of paraquat from the gastrointestinal tract, activated charcoal $1 \mathrm{~g} / \mathrm{kg}$ added to $250 \mathrm{~mL}$ of magnesium citrate was given through a nasogastric tube after gastric lavage with normal saline. In addition, all patients received two doses of 8-hr active charcoal-containing haemoperfusion therapy in the emergency room.' p.369

The control group received: 'After haemoperfusion therapy, the control group received dexamethasone $5 \mathrm{mg}$ in an intravenous injection every $6 \mathrm{hrs}$ until their arterial blood gas showed $\mathrm{PaO} 211.5 \mathrm{kPa}(80 \mathrm{~mm} \mathrm{Hg})$ or they died.' p.369

The intervention group received: 'At the same time, the study group received pulse therapy with $15 \mathrm{mg} / \mathrm{kg}$ cyclophosphamide in $5 \%$ glucose saline $200 \mathrm{~mL}$ and $1 \mathrm{~g}$ of methylprednisolone in the other $200 \mathrm{~mL}$ of $5 \%$ glucose saline intravenously infused for 2 hrs per day. Cyclophosphamide was infused for 2 days and methylprednisolone for 3 day simultaneously. Preceding dexamethasone, a 5-mg intravenous injection every 6 hrs was given until the arterial blood gas showed $\mathrm{PaO} 211.5 \mathrm{kPa}(80 \mathrm{~mm} \mathrm{Hg})$. Repeated pulse therapy with $1 \mathrm{~g}$ of methylprednisolone in the other $200 \mathrm{~mL}$ of $5 \%$ glucose saline intravenously infused for 2 hrs per day for 3 days was given again if $\mathrm{PaO} 2$ was 8.64 $\mathrm{kPa}(60 \mathrm{~mm} \mathrm{Hg})$. In addition, $15 \mathrm{mg} / \mathrm{kg} /$ day cyclophosphamide was infused for 1 day again if patients' white cell counts were $3000 / \mathrm{m} 3$ and the duration was 2 wks after initial cyclophosphamide pulse therapy to avoid a severe leukopenia episode.' p.369

Outcomes

Notes
Mortality.

Participants were followed up for six weeks.

Recruitment was from January 1999 to December 2003.

Intervention Group: 16 participants. 11 were male, 5 were female. Poisoning severity: 5 navy blue, 11 dark blue 
Lin 2006 (Continued)

Control Group: 7 participants. 5 were male, 2 were female. Poisoning severity: 1 navy blue, 6 dark blue

\begin{tabular}{|c|c|c|}
\hline Item & Authors' judgement & Description \\
\hline Adequate sequence generation? & Yes & $\begin{array}{l}\text { 'All study patients were randomly allocated to control } \\
\text { and study groups in the proportion of } 1: 2 \text { by means of a } \\
\text { sequence of labelled cards contained in sealed numbered } \\
\text { envelopes that were prepared by a statistical adviser.' p. } \\
369\end{array}$ \\
\hline Allocation concealment? & Yes & $\begin{array}{l}\text { '...(the envelope was) opened by the researcher in the } \\
\text { presence of patients.' p. } 369\end{array}$ \\
\hline $\begin{array}{l}\text { Blinding? } \\
\text { All outcomes }\end{array}$ & No & $\begin{array}{l}\text { 'Neither stratification nor blinding was made in this } \\
\text { study.' p.369 'The data were collected and analysed by } \\
\text { other doctors not familiar with the study.' p. } 369\end{array}$ \\
\hline $\begin{array}{l}\text { Incomplete outcome data addressed? } \\
\text { All outcomes }\end{array}$ & Yes & $\begin{array}{l}\text { The main outcome was death at final follow-up, and this } \\
\text { was reported in full }\end{array}$ \\
\hline Free of selective reporting? & Yes & $\begin{array}{l}\text { The study reported the main outcome, death at final } \\
\text { follow-up, in full }\end{array}$ \\
\hline Free of other bias? & Yes & $\begin{array}{l}\text { We did not identify any other areas of bias. The inclusion } \\
\text { criterion, using the Hart } 1984 \text { predictive mortality scale, } \\
\text { was the main area for bias in this study (i.e. patients with } \\
\text { a predicted mortality of } \geq 90 \% \text { or }<50 \% \text { were excluded } \\
\text { from the trial) }\end{array}$ \\
\hline
\end{tabular}

\section{Characteristics of excluded studies [ordered by study ID]}

\begin{tabular}{ll}
\hline Study & Reason for exclusion \\
\hline Perriens 1992 & $\begin{array}{l}\text { It was a historically controlled study, not randomised. 'Patients admitted before October 10, 1986 received the } \\
\text { standard treatment only, because i.v. cyclophosphamide and i.v. dexamethasone were not available in Suriname until } \\
\text { that time. Patients presenting after October 10, 1986 received high-dose cyclophosphamide and dexamethasone } \\
\text { treatment, in addition to standard treatment.' p130 }\end{array}$ \\
\hline Tsai 2009 & This study focused on methylprednisolone only. \\
\hline
\end{tabular}




\section{Characteristics of ongoing studies [ordered by study ID]}

\section{Ariyananda 2006}

\begin{tabular}{|c|c|}
\hline Trial name or title & A randomised controlled trial of high-dose immunosuppression in paraquat poisoning. (ISRCTN85372848) \\
\hline Methods & Randomised controlled trial. \\
\hline Participants & $\begin{array}{l}\text { Patients with paraquat poisoning. } \\
\text { Sample size: } 600 \text { ( } 300 \text { active, } 300 \text { placebo) }\end{array}$ \\
\hline Interventions & $\begin{array}{l}\text { Intervention: Two days of cyclophosphamide } 750 \mathrm{mg} \text { (if weight is less than } 50 \mathrm{~kg} \text { ) or one gram (if weight } \\
\text { is more than } 50 \mathrm{~kg} \text { ), and three days of methylprednisolone one gram both by intravenous infusion over one } \\
\text { hour. Steroids in the form of oral dexamethasone ( } 8 \mathrm{mg} \text { three times daily) will be continued for the next two } \\
\text { weeks. Patients will receive mesna } 400 \mathrm{mg} \text { intravenous at start of therapy and four and eight hours later to } \\
\text { reduce risk of haemorrhagic cystitis } \\
\text { Control: Control patients will receive saline placebo infusion and placebo capsules }\end{array}$ \\
\hline Outcomes & $\begin{array}{l}\text { Primary: All-cause mortality in hospital. } \\
\text { Secondary: } 1 \text {. All-cause mortality at three months post-ingestion. } 2 \text {. Lung function in survivors at three } \\
\text { months }\end{array}$ \\
\hline Starting date & 30 August 2006 \\
\hline Contact information & $\begin{array}{l}\text { Contact person: Pilane Liyanage Ariyananda } \\
\text { South Asian Clinical Toxicology Research Collaboration (SACTRC) (Sri Lanka) } \\
\text { SACTRC Department of Medicine University of Peradeniya } \\
20000 \\
\text { Peradeniya } \\
\text { Sri Lanka } \\
+94(0) 812384556 \\
\text { ariyananda@sltnet.lk }\end{array}$ \\
\hline Notes & $\begin{array}{l}\text { Sponsors: 1. Syngenta Crop Protection AG (USA) 2. The Wellcome Trust (UK) (Grant reference number: } \\
071669 \text { ) }\end{array}$ \\
\hline
\end{tabular}


DATA AND ANALYSES

Comparison 1. All-cause mortality at final follow-up

\begin{tabular}{lcccc} 
Outcome or subgroup title & $\begin{array}{c}\text { No. of } \\
\text { studies }\end{array}$ & $\begin{array}{c}\text { No. of } \\
\text { participants }\end{array}$ & Statistical method & Effect size \\
\hline $\begin{array}{l}\text { 1 All-cause mortality at final } \\
\text { follow-up }\end{array}$ & 3 & 164 & Risk Ratio (M-H, Fixed, 95\% CI) & $0.72[0.59,0.89]$ \\
\hline
\end{tabular}

Analysis I.I. Comparison I All-cause mortality at final follow-up, Outcome I All-cause mortality at final follow-up.

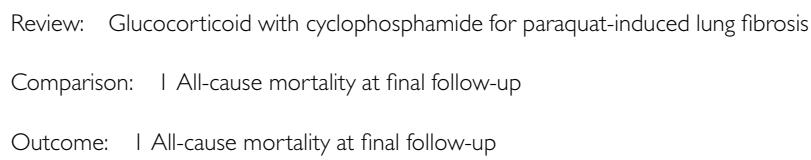

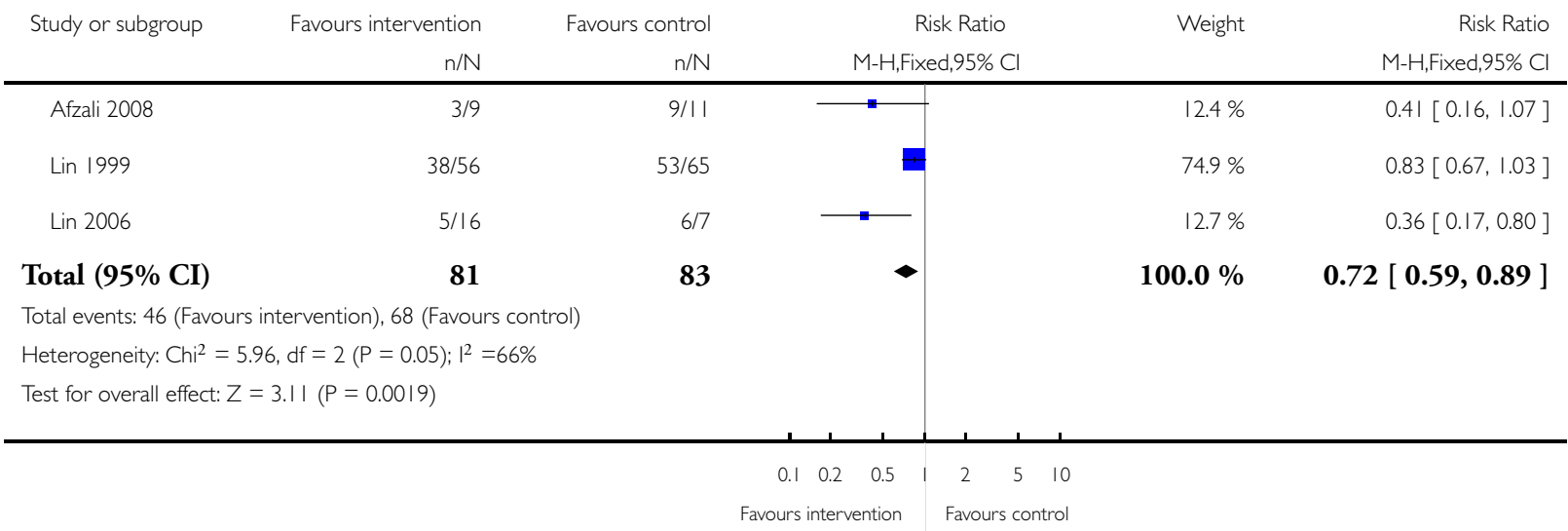


A P P E N DICES

\section{Appendix I. MEDLINE search strategy}

Ovid MEDLINE(R) 1950 to July Week 1 2009. This strategy was formulated by the Cochrane Injuries Group's Trials Search Coordinator. It was then translated and adapted for use in Chinese language databases by review author Luying Ryan Lee.

1.exp Herbicides/

2.exp Paraquat/

3.(Paraquat or (methyl adj3 viologen) or gramoxone or paragreen or Herbicide* or Pyridinium Compound*).mp.

4.1 or 2 or 3

5.exp Lung Diseases/

6.exp Pulmonary Fibrosis/

7.((Pulmonary or lung) adj3 (fibrosis or fibroses)).ab,ti.

8.((Alveolitis or alveolitides) adj3 fibrosing).ab,ti.

9.5 or 6 or 7 or 8

10.exp Glucocorticoids/

11.glucocorticoid*.ab,ti.

12.exp Cyclophosphamide/

13. (Cyclophosphamide* or cytophosphan or cyclophosphane or procytox or sendoxan or b-518 or neosar or cytoxan or endoxan or nsc-26271).ti,ab.

14.10 or 11 or 12 or 13

15.randomi?ed.ab,ti.

16.randomized controlled trial.pt.

17.controlled clinical trial.pt.

18.placebo.ab.

19.clinical trials as topic.sh.

20.randomly.ab.

21.trial.ti.

22.15 or 16 or 17 or 18 or 19 or 20 or 21

23. (animals not (humans and animals)).sh.

24.22 not 23

25.4 and 9 and 14 and 24

\section{Appendix 2. Search strategy: Chinese language databases (English translation)}

CBM (1978-September 2009), CMCC (1995-September 2009), CMAC (1994-September 2009)

1.exp herbicide/

2.exp paraquat/

3. 1 or 2

4.exp lung disease/

5.exp pulmonary fibrosis/

6.4 or 5

7.exp corticosteroids/

8.steroids*.ab,ti.

9.exp cyclophosphamide/

10.7 or 8 or 911 .(randomised).ab,ti.

12.randomized controlled study.pt.

13. clinical controlled study.pt.

14.randomly.ab.

15.trail.ti.

16.11 or 12 or 13 or 14 or 15.17 .3 and 6 and 10 and 16 .

Glucocorticoid with cyclophosphamide for paraquat-induced lung fibrosis (Review) 


\section{Appendix 3. Search strategy: English language databases}

\section{Cochrane Injuries Group's Specialised Register (searched 15 Sept 2009)}

1.(Paraquat or (methyl and viologen) or Dimethyl* or gramoxone or grammoxone or paragreen or Herbicide* or "Pyridinium compound" or pathclear or weedol)

2.(cyclophosphamid* or carloxan or clafen or cycloblastin or cycloblastine or "cyclofos amide" or cyclofosfamid or cyclofosfamide or cyclophosphan* or cycloxan or cyphos or cytophosphan* or cytoxan or "endocyclo phosphate" or endoxan* or enduxan or "genoxalor mitoxan" or neosan or neosar or noristan or "nsc 26271 " or "nsc 2671 " or b-51

3.1 and 2

CENTRAL (The Cochrane Library 2009, Issue 3)

\#1MeSH descriptor Herbicides explode all trees

\#2MeSH descriptor Paraquat explode all trees

\#3(Paraquat or (methyl near3 viologen) or Dimethyl* or gramoxone or grammoxone or paragreen or Herbicide* or Pyridinium compound* or pathclear or weedol)

\#4 (\#1 OR \#2 OR \#3)

\#5MeSH descriptor Glucocorticoids explode all trees

\#6MeSH descriptor Cyclophosphamide explode all trees

\#7(cyclophosphamid* or carloxan or clafen or cycloblastin or cycloblastine or cyclofos amide or cyclofosfamid or cyclofosfamide or cyclophosphan*or cycloxan or cyphos or cytophosphan* or cytoxan or endocyclo phosphate or endoxan* or enduxan or genoxalor mitoxan or neosan or neosar or noristan or nsc 26271 or nsc 2671 or b-518 or procytox* or semdoxan or sendoxan)

\#8 (\#5 OR \#6 OR \#7)

\#9(\#4 AND \#8)

MEDLINE (Ovid SP) 1950 September Week 12009

1.exp Herbicides/

2.exp Paraquat/

3.(Paraquat or (methyl adj3 viologen) or Dimethyl* or gramoxone or grammoxone or paragreen or Herbicide* or Pyridinium compound* or pathclear or weedol).mp.

4.1 or 2 or 3

5.exp Lung Diseases/

6.exp Pulmonary Fibrosis/

7.((Pulmonary or lung) adj3 (fibrosis or fibroses)).ab,ti.

8.((Alveolitis or alveolitides) adj3 fibrosing).ab,ti.

9.5 or 6 or 7 or 8

10.exp Glucocorticoids/

11.glucocorticoid*.ab,ti.

12.exp Cyclophosphamide/

13. (cyclophosphamid* or carloxan or clafen or cycloblastin or cycloblastine or cyclofos amide or cyclofosfamid or cyclofosfamide or cyclophosphan*or cycloxan or cyphos or cytophosphan* or cytoxan or endocyclo phosphate or endoxan* or enduxan or genoxalor mitoxan or neosan or neosar or noristan or nsc 26271 or nsc 2671 or b-518 or procytox* or semdoxan or sendoxan).ab,ti.

14.10 or 11 or 12 or 13

15.4 and 9 and 14

16.(animals not (humans and animals)).sh.

17.15 not 16

EMBASE (Ovid SP) 1980 to 2009 Week 37

1.exp Herbicide/

2.exp Paraquat/

3.exp pyridinium derivative/

4.(Paraquat or (methyl adj3 viologen) or Dimethyl* or gramoxone or grammoxone or paragreen or Herbicide* or Pyridinium compound* or pathclear or weedol).mp.

5.1 or 2 or 3 or 4

6.exp Lung Disease/

7.exp lung fibrosis/

8.((Pulmonary or lung) adj3 (fibrosis or fibroses)).ab,ti.

Glucocorticoid with cyclophosphamide for paraquat-induced lung fibrosis (Review)

Copyright $\odot 2010$ The Cochrane Collaboration. Published by John Wiley \& Sons, Ltd. 
9.((Alveolitis or alveolitides) adj3 fibrosing).ab,ti.

10.6 or 7 or 8 or 9

11.exp Glucocorticoids/

12.glucocorticoid*.ab,ti.

13.exp Cyclophosphamide/

14.exp cyclophosphamide derivative/

15. (cyclophosphamid* or carloxan or clafen or cycloblastin or cycloblastine or cyclofos amide or cyclofosfamid or cyclofosfamide or cyclophosphan*or cycloxan or cyphos or cytophosphan* or cytoxan or endocyclo phosphate or endoxan* or enduxan or genoxalor mitoxan or neosan or neosar or noristan or nsc 26271 or nsc 2671 or b-518 or procytox* or semdoxan or sendoxan).ab,ti.

16.11 or 12 or 13 or 14 or 15

17.5 and 10 and 16

18.exp animal/ not (exp human/ and exp animal/)

19.17 not 18

ISI Web of Science: Science Citation Index Expanded (SCI-EXPANDED) 1970 to Sept 2009 and ISI Web of Science: Conference Proceedings Citation Index-Science (CPCI-S) 1990 to Sept 2009

1.(Paraquat or or Dimethyl* or gramoxone or grammoxone or paragreen or Herbicide* or or pathclear or weedol or Pyridinium compound*) or (methyl same viologen)

2.(cyclophosphamid* or carloxan or clafen or cycloblastin or cycloblastine or cyclofos amide or cyclofosfamid or cyclofosfamide or cyclophosphan* or cycloxan or cyphos or cytophosphan* or cytoxan or endocyclo phosphate or endoxan* or enduxan or genoxalor mitoxan or neosan or neosar or noristan or nsc 26271 or nsc 2671 or b-518 or procytox* or semdoxan or sendoxan)

3.((Pulmonary or lung) SAME (fibrosis or fibroses)) OR ((Alveolitis or alveolitides) SAME fibrosing) OR (lung* SAME disease*)

4.1 and 2 and 3

\section{H I S T O R Y}

Protocol first published: Issue 4, 2009

Review first published: Issue 6, 2010

\section{CONTRIBUTIONSOFAUTHORS}

Luying Ryan Li (LL) and Chao You (CY) were responsible for writing the protocol. Bhuwan Chaudhary (BC) and LL selected the trials from English language databases. LL and YC selected trials from Chinese language databases. YC offered interpretation of the clinical features of paraquat poisoning and arbitrated on the inclusion of one trial (Afzali 2008). Emma Sydenham (ES), LL and $\mathrm{BC}$ independently assessed the risk of bias in the included trials and extracted data. LL and ES interpreted the data and wrote the manuscript. All authors agreed on the final manuscript.

\section{DECLARATIONS OF INTEREST}

None known. 


\section{DIFFERENCES BETWEEN PROTOCOLANDREVIEW}

We (LL and BC) were unable to hand search conference abstracts because our university library did not have any relevant abstracts in the collection.

Emma Sydenham was added as an author.

\section{N D EX TERMS}

\section{Medical Subject Headings (MeSH)}

Cyclophosphamide [*therapeutic use]; Drug Therapy, Combination [methods]; Glucocorticoids [*therapeutic use]; Paraquat [* poisoning]; Pulmonary Fibrosis [chemically induced; *drug therapy; immunology]; Randomized Controlled Trials as Topic

\section{MeSH check words}

Humans 